\title{
GESTÃO DE RESÍDUOS SÓLIDOS \& A CIDADE - CASO NO LITORAL DO ESTADO DE SAO PAULO
}

\author{
Ana Paula Rattis Alipio ${ }^{1}$
}

Gilda Collet Bruna²

RESUMO: Toda a sociedade moderna de alguma maneira vive com as consequências de descasos ambientais. A transformação da cidade agrária para urbana traz mudanças para o meio ambiente, pois o aumento do número de pessoas em uma cidade em que o crescimento não é organizado ou planejado contribui para o aumento de poluição. $O$ crescimento da maioria das cidades brasileiras não foi concomitante com o a infraestrutura de serviços públicos ou saneamento básico. Por isso também, o agravamento dos problemas ambientais urbanos, oriundos de poluição é crescente no Brasil. A disposição de lixo em lugares inadequados devido a ausência de planejamento ou carência de sistemas de gestão e manejo de resíduos sólidos gera inúmeros danos ao meio ambiente urbano como: proliferação de vetores de doenças (moscas, ratos, baratas); poluição do ar causada por fumaça proveniente do lixo exposto; gases de efeito estufa e poluição do ar; contaminação do solo, pelo chorume e enchentes. Diante dessa situação torna-se necessário desenvolver uma tecnologia para a reciclagem dos RSU descartados. O objetivo desse artigo é analisar esse Sistema de Gestão buscando estendê-lo para outras

\footnotetext{
${ }^{1}$ ALIPIO, Ana Paula Rattis Alipio, Possui graduação em Arquitetura e Urbanismo pelo Centro Universitário Belas Artes de São Paulo (2001) ; mestrado em Arquitetura e Urbanismo pela Universidade Presbiteriana Mackenzie (2010) e Doutoranda do Programa de pós Graduação em Arquitetura e Urbanismo da Universidade Presbiteriana Mackenzie ( 2012).

E-mail: arq@a-arquitetura.com

2 Docente da Universidade Presbiteriana Mackenzie - E-mail: Gilda@mackenzie.br
} 
áreas como bairros e comunidades que sofrem com a falta de gerenciamento de Resíduo Sólido Urbano. Para tanto focaliza urbanizações existentes no litoral do estado de São Paulo, focalizando um sistema de resíduos sólidos existente, e sua eficiência como sistema patrocinado e alimentado pela iniciativa privada.

Palavras-Chave: Resíduos Sólidos Urbanos (RCD). Reciclagem. Sistema de Gestão Ambiental.

\section{INTRODUÇÃO}

As cidades crescem continuamente e a qualidade urbana não alcança este crescimento urbano, devido à falta de infraestrutura de saneamento ou mesmo de serviços urbanos. A sociedade moderna em seu desenvolvimento, sua produção e consumo, gera grande quantidade de resíduos sólidos urbanos. Por isso é necessário que possa contar com um planejamento e gestão desses resíduos. A disposição inadequada dos resíduos sólidos provoca alterações no meio ambiente, alterando a qualidade do solo, do ar e dos corpos aquáticos, representando assim um risco para a saúde pública. (ALIPIO, 2013).

A coleta seletiva não é nenhuma novidade, pois hoje em muitos países já faz parte do dia a dia da população, sendo considerada mesmo parte da infraestrutura da cidade. 


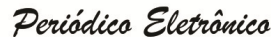 Fórum Ambiental}
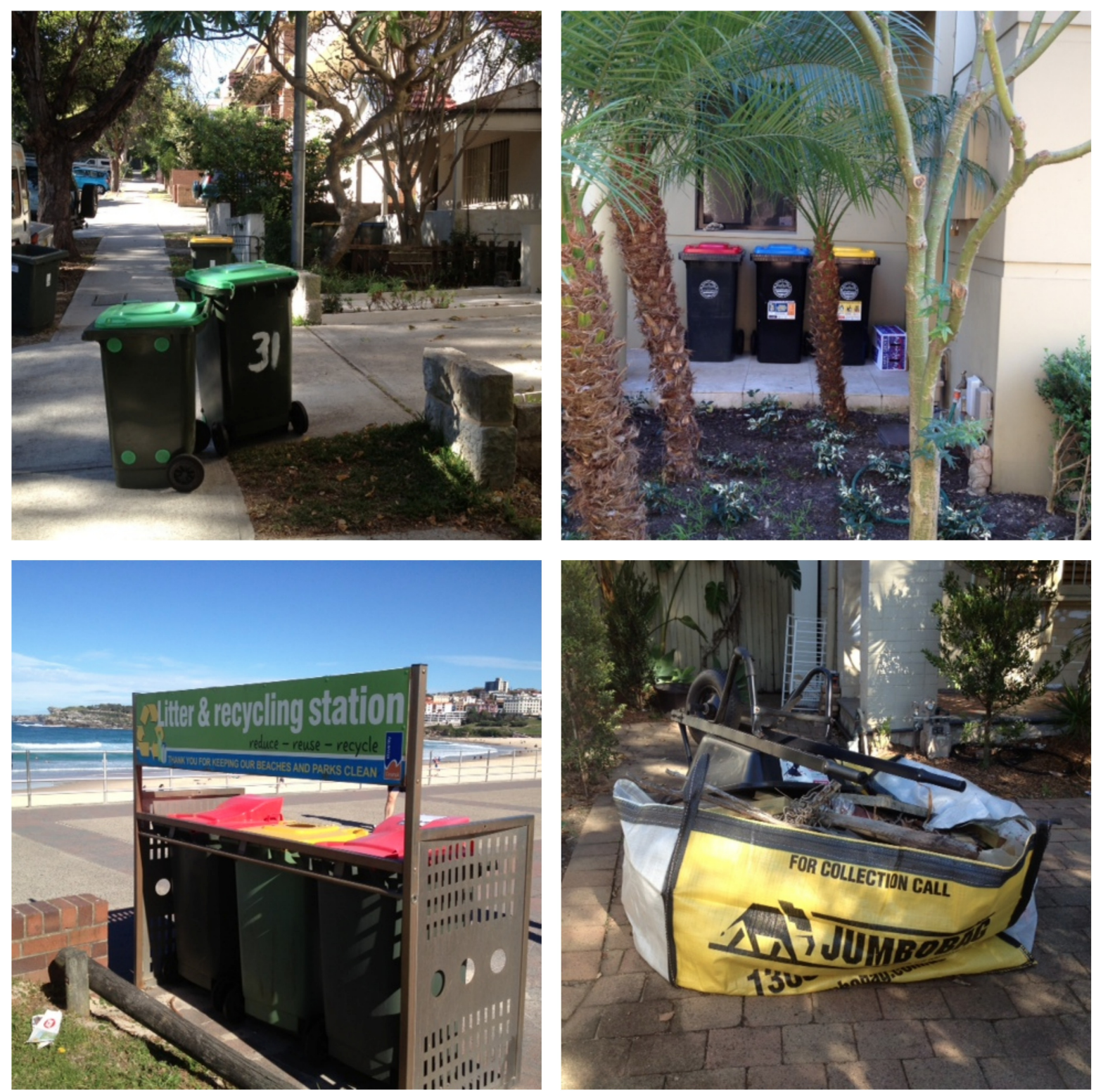

Figura 1 - Fotos por Ana Alipio, Tiradas em Sydney Austrália. Mostram a organização municipal e o gerenciamento de lixo em toda a cidade. (montagem criada no programa foto photo, editada por Alipio, 2013) 

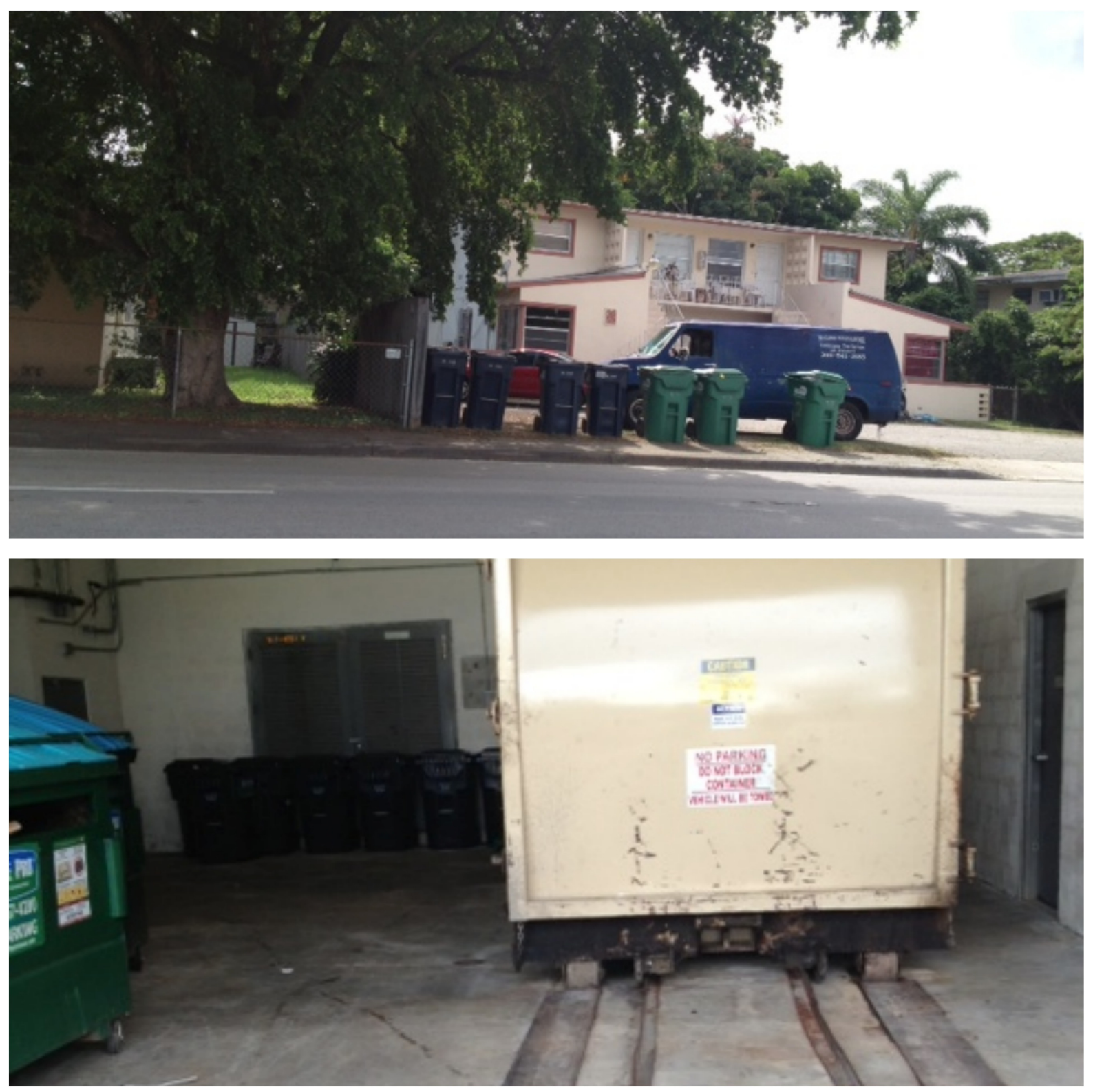

Figura 2 - Fotos por Ana Alipio, Tiradas em Miami - Florida. Mostram a organização municipal e seu gerenciamento de lixo em toda a cidade; (montagem criada no programa foto photo, editada por Alipio, 2013)

O primeiro passo, para que uma cidade sem apoio de num sistema de reciclagem de lixo urbano é poder contar com um setor de gerenciamento de resíduos. No Brasil hoje se tem alguns exemplos como: José do Rio Preto; Americana; e Sta. Bárbara do Oeste. Estas são cidades que praticam o Gerenciamento de Resíduos. (PINTO, 2008). Porem, esses casos são praticamente raridade no país. No Brasil infelizmente a infraestrutura urbana ainda não atende à demanda de descarte de resíduos. Entende-se que resíduos 
sólidos urbanos englobem: os resíduos domiciliares, originários de atividades domésticas e residências urbanas bem como os resíduos de limpeza urbana, originários da varrição, limpeza de logradouros e vias públicas (SMA-CETESB- ABES, 2011).

Para a análise proposta por esse artigo, toma-se o estudo de caso da Riviera de São Lourenço, bairro localizado em um Bairro do Litoral Paulista - UIT3 Riviera de São Lourenço, Bertioga, $\mathrm{SP}^{3}$. Esse bairro litorâneo conta com um Sistema de Gestão de Resíduos Sólidos Urbanos eficientes, como mostram os indicadores de sustentabilidade da Riviera de São Lourenço ${ }^{4}$. Este artigo relaciona as leis que tratam dessa problemática de indicadores. Em destaque a Lei 12.305/10, lei federal que institui a Política Nacional de resíduos Sólidos; altera a lei 9.605 de 12 de fevereiro de 1998; e dá outras providências ${ }^{5}$. E que em seu artigo 9o, destaca-se que "na gestão e gerenciamento de resíduos sólidos, deve ser observada a seguinte ordem de prioridade: não geração, redução, reutilização, reciclagem, tratamento dos resíduos sólidos e disposição final ambientalmente adequada dos rejeitos". E a Lei de Saneamento Básico 11.445 de 5 de janeiro de $2007^{6}$, que estabelece diretrizes nacionais para o saneamento básico; altera as leis ํㅡ 6.766 de 19 de dezembro de 1979; 8.036 de 11 de maio de 990; 8.666 de 21 de junho de 1993; 8.987 de 3 de fevereiro de 1995; revoga a lei o 6.528 de 11 de maio de 1978; e dá outras providências. Destaca-se assim que esta lei em seu artigo 1o "estabelece as diretrizes nacionais para o saneamento básico e para a política federal de saneamento básico" e em seu artigo $2^{\circ}$ define que "os serviços públicos de saneamento básico serão prestados com base [em] (...) princípios fundamentais". Em seu artigo $3^{\circ}$ define o que essa lei considera, sendo assim, com relação ao inciso I- saneamento básico: conjunto de serviços, infraestruturas e instalações operacionais. No item c, descreve o tratamento que se deve dar aos resíduos sólidos urbanos, mencionando a "limpeza urbana e manejo de resíduos sólidos, como um conjunto de atividades, infraestruturas e instalações operacionais de coleta, transporte, transbordo, tratamento e destino final do lixo doméstico e do lixo originário da varrição e limpeza de logradouros e vias públicas".

\footnotetext{
${ }^{3}$ Governo do Estado de São Paulo. AGEM, Agência Metropolitana da Baixada Santista. Região Metropolitana da baixada Santista. Região Metropolitana da Baixada Santista. Padrões Sócioespaciais. Bertioga. UITs 2004, 2005.

${ }^{4}$ Indicadores de Sustentabilidade da Riviera de São Lourenço. In http://www.rivieradesaolourenco.com/indicadores-de-sustentabilidade-da-riviera-de-sao-lourenco/; acesso em 06/10/2013.

${ }^{5}$ http://www.planalto.gov.br/ccivil 03/ ato2007-2010/2010/lei//12305.htm; acesso 06/10/2012.

6 http://www.planalto.gov.br/ccivil 03/ ato2007-2010/2007/lei//11445.htm; acesso 06/10/2013.
} 
Desse modo, a partir dessas legislações nacionais é que se pode verificar a aplicabilidade dessas leis sobre o bairro estudado. Assim propõe-se investigar como a GRS (Gestão de Resíduos Sólidos) funciona no local. O foco é sobre a tecnologia e organização usada nesse bairro. Espera-se que a esse estudo possa resultar em recomendações para serem executadas em bairro de baixa renda, como o bairro vizinho de Indaiá, que tem crescido de maneira desorganizada sem planejamento, e já acumula entulho nos seus terrenos baldios como a maioria dos bairros de baixa renda do pais.

\section{A GESTÃo DE RESÍDUOS NO LITORAL DO ESTADO DE SÃO PAULO}

A gestão de Resíduos Sólidos no Litoral recebe maiores pressões na época de temporada, pois a quantidade de pessoas se multiplica e, em consequência, multiplica-se a quantidade de resíduo urbano produzido. Assim agravam-se os problemas com as empresas responsáveis pelo recolhimento e processamento do lixo como uma questão de saneamento básico.

De acordo com o Diretor da Sobloco ${ }^{7}$, Luiz Augusto Pereira de Almeida, além dos problemas relacionados à vida urbana, "esgoto é a que mais impacta o meio ambiente das estâncias turísticas e a que recebe menos atenção por parte da administração pública". Consequentemente a ausência de serviços como esses leva ao aumente de doenças e como resultado, aumenta também a necessidade de serviços básicos de saúde como hospitais e leitos, naqueles locais onde é premente levar o saneamento.

Pode-se observar que a grande "fonte de doença" está na insalubridade ambiental, como diz a notícia de jornal abaixo:

[...] em matéria de O Estado de S. Paulo, divulgou-se que quase a metade do esgoto produzido nas 13 cidades do litoral paulista era despejada no mar ou no lençol freático, por fossas sépticas. Os números eram reveladores: 1,5 mil litros de esgoto por segundo, o suficiente para encher em uma hora duas piscinas olímpicas de 2,5 milhões de litros cada. É mais do que lógico que, com o lançamento de esgotos a céu aberto, contaminando rios, mares, lençóis freáticos, praias e o meio ambiente, a população do entorno seja diretamente afetada e os problemas de saúde proliferem (Apud ALMEIDA, 2013).

\footnotetext{
${ }^{7}$ Construtora Sobloco SA em presa, construtora, desde 1958. Constroe: empreendimentos, hotéis, edifícios, shopping centers ( fonte: http://www.sobloco.com.br/site/interno.asp?keyword=realizacoes. desenvolvimento acesso 01 de setembro de 2013)
} 
A situação do litoral norte é precária nesse sentido, pois não há condições adequadas para coleta de resíduos na maioria de sua área, acarretando cada vez mais depósito em locais impróprios e gerando mais poluição. A grande maioria desses resíduos sólidos acaba sendo depositada em lixões ou terrenos vazios. Em 1991, o IBGE inicia um levantamento de "lixo coletado" e "outros destinos", podendo-se observar na Tabela 1 Destino do Lixo, mostrando em porcentagens a quantidade de domicílios particulares permanentes, por municípios do Litoral Norte do estado de São Paulo (PANIZZA, 2004).

TABELA 1 - DESTINO DO LIXO

\begin{tabular}{|c|c|c|c|c|c|c|c|c|c|}
\hline & & Caraguatatuba & $\%$ & Ubatuba & $\%$ & São Sebastião & $\%$ & Ilhabela & $\%$ \\
\hline \multirow[t]{3}{*}{1991} & $\begin{array}{l}\text { Domicilios } \\
\text { particulares } \\
\text { permanentes }\end{array}$ & $\begin{array}{c}13.075 \\
\left(38,0 \%{ }^{*}\right)\end{array}$ & 100 & $\begin{array}{c}11.460 \\
(37,4 \%)\end{array}$ & 100 & $\begin{array}{c}8.363 \\
(42,6 \% *)\end{array}$ & 100 & $\begin{array}{c}3.393 \\
\left(52,7^{*}\right)\end{array}$ & 100 \\
\hline & Lixo coletado & 11.997 & 91,8 & 10.068 & 87,9 & 7.609 & 91,0 & 2.836 & 83,6 \\
\hline & Outro destino & 1.078 & 8,2 & 1.392 & 12,1 & 754 & 9,0 & 557 & 16,4 \\
\hline \multirow[t]{3}{*}{2000} & $\begin{array}{l}\text { Domicilios } \\
\text { particulares } \\
\text { permanentes }\end{array}$ & $\begin{array}{c}22.164 \\
(42,5 \% *)\end{array}$ & 100 & $\begin{array}{c}18.150 \\
(39,2 \% *)\end{array}$ & 100 & $\begin{array}{c}16.271 \\
\left(49,2 \% \%^{*}\right)\end{array}$ & 100 & $\begin{array}{c}5.736 \\
\left(58,5 \% \%^{*}\right)\end{array}$ & 100 \\
\hline & Lixo coletado & 21.601 & 97,5 & 17.700 & 97,5 & 15.990 & 98,3 & 5.442 & 94,9 \\
\hline & Outro destino & 563 & 2,5 & 450 & 2,5 & 281 & 1,7 & 294 & 5,1 \\
\hline
\end{tabular}

* Porcentagem dos "domicilios particulares permanentes" segundo o "total de domicilios".

Fonte: IBGE, Censos Demográficos, anos 1980, 1991, 2000.

Essa tabela mostra que o lixo ou é coletado pelo serviço do município junto a suas prefeituras ou a população é que se encarrega de descartá-lo e normalmente de forma precária.

De acordo com Panizza (2004), "nenhum dos municípios do Litoral Norte Paulista possui aterro sanitário, sendo assim mesmo coletado pelos serviços das Prefeituras Municipais e tem seu destino final em um lixão". O deposito de lixo em áreas de preservação ambiental é inapropriado assim como, o depósito em áreas de proteção aos mananciais, como em APP, Áreas de Preservação Permanente ${ }^{8}$. No Estado de São Paulo, a Lei 4435/84, veda a instalação de depósito de lixo, usinas de beneficiamento de resíduos

\footnotetext{
${ }^{8}$ Área de Preservação Permanente - APP são as áreas que compreendem as florestas e demais formas de vegetação natural, conforme definidas no artigo 2ํㅡㄹ da Lei Federal ํㅜ 4.771, de 15 de setembro de 1965 Código Florestal; (Fonte :

http://www3.prefeitura.sp.gov.br/cadlem/secretarias/negocios_juridicos/cadlem/integra.asp?alt=11102007PL0 06712007CAMARA acesso 07 de Outubro de 2013)
} 
sólidos e aterros sanitários em área que especifica. ${ }^{9}$

Deste modo, a formação da urbanização da área do entorno da praia de São Lourenço é uma exceção, pois ao constituir o bairro Riviera de São Lourenço e o respectivo Sistema de Gestão de Resíduos inova e protege ambientalmente a população.

Ora, segundo Gomes, Aquino e Colturato (2012), a prática costumeira em todo o litoral é a deposição em lixões ou lugares inadequados, aumentando a emissão dos gases. Para minimizar essa prática, alguns municípios optam pela utilização por aterros sanitários, embora não utilizada em países desenvolvidos (GOMES, AQUINO e COLTURATO, 2012).

\begin{tabular}{|l|c|l|l|}
\hline Município & $\begin{array}{c}\text { População } \\
\text { em 2010 }\end{array}$ & $\begin{array}{c}\text { Criação do programa } \\
\text { de coleta seletiva }\end{array}$ & \multicolumn{1}{|c|}{ Desenho adotado } \\
\hline Bertioga & $\mathbf{4 7 . 5 7 2}$ & Dez/2011 & 52LEVs porta a porta(parcial) \\
\hline Cubatão & 118.797 & Jun/2012 & 28 PEVs \\
\hline Guarujá & 290.607 & Out/2006 & 170 PEVs \\
\hline Itanhaém & 87.053 & Mar/2005 & $\begin{array}{l}\text { PEVs Porta a porta (parcial com } \\
\text { início em 2009) }\end{array}$ \\
\hline Mongaguá & 46.301 & Não institucionalizada & Projeto piloto com a Coopemar \\
\hline Peruíbe & 59.793 & 2010 & PEVs porta a porta \\
\hline Praia Grande & 260.769 & s.i. & Porta a porta \\
\hline Santos & 419.757 & $\mathbf{1 9 9 0}$ & Porta a Porta \\
\hline São Vicente & 332.424 & Mai/1997 & PEVs porta a porta \\
\hline
\end{tabular}

Fonte: Dias 2013

No quadro acima o município de Santos aparece como percussor em 1990, com criação de coleta seletiva, pois nessa época a cidade de Bertioga e Riviera de São Lourenço eram bairros pertencentes à cidade de Santos. Assim o percussor foi o bairro de Riviera de São Lourenço, que será objeto de nosso estudo (ALIPIO, 2013).

\section{GERENCIAMENTO DE RESÍDUOS SÓLIDOS RIVIERA DE SÃO LOURENÇO}

A coleta seletiva deverá ser implementada mediante a separação prévia dos

${ }^{9}$ http://governo-sp.jusbrasil.com.br/legislacao/195850/lei-4435-84?ref=home acesso 07 de Outubro de 2013 
resíduos sólidos (nos locais onde são gerados), conforme sua constituição ou composição (úmidos, secos, industriais, da saúde, da construção civil, etc.). A implantação do sistema de coleta seletiva é instrumento essencial para se atingir a meta de disposição final ambientalmente adequada dos diversos tipos de rejeitos. (MINISTÉRIO DO MEIO AMBIENTE, 2012, p. 23)

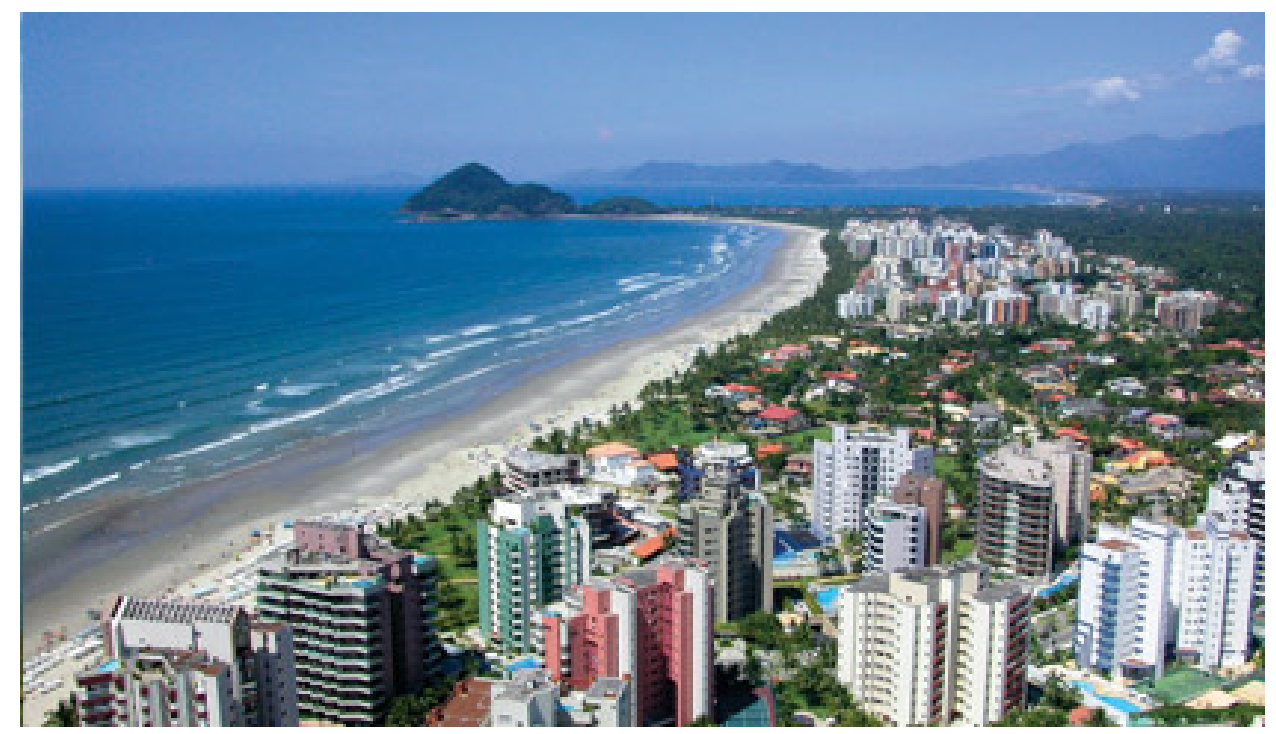

Figura 3- Fonte: Foto aérea da Riviera de São Lourenço. http://www.rivieradesaolourenco.com/sobre/o-projeto/ acesso 29 de setembro de 2013

O Projeto de urbanização da Riviera de São Lourenço iniciou-se em 1979. Durante esse período um grupo de investidores, diretores das empresas Praias Paulistas S/A. e Cia. Fazenda Acaraú, com uma parceria com a Sobloco construtora S/A, planejaram o projeto urbano para uma área de 9 milhões de metros quadrados, que se antecipou às leis de urbanização, leis ligadas ao meio ambiente, integraram uma comunidade em um modelo sustentável de ocupação urbana. Esse projeto tem sido partilhado, pela Sobloco e pelas empresas proprietárias das terras, a Praias Paulistas e Cia. Fazenda Acaraú, e mais tarde, pelas empresas que se originaram das cisões destas (MAZZOLENIS, 2008 p. 09). A RSL tem em seu planejamento preocupação com as Águas, Solo, Resíduos Sólidos, Planejamento Ambiental, , Fiscalização Ambiental, preocupação com a Vida Animal, Licença Ambiental e Educação Ambiental.

O Sistema de Gestão de Resíduos existente no bairro , assim como todos seu 


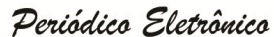 Fórum Ambiental}

da Alta Paulista

ISSN 1980-0827

Volume 9, Número 4, 2013

Dilemas da

Sustentabilidade Urbana

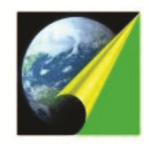

ANAP

saneamento básico e esgotos, o seu próprio planejamento urbano além de planejamento na construção funcionam de modo exemplar, de forma a cumprir diversos requisitos ligados a sustentabilidade inclusive em suas obras, antes mesmo de surgirem leis como como CONAMA 305 , Lei 12.305/10 ou 11.445/07.

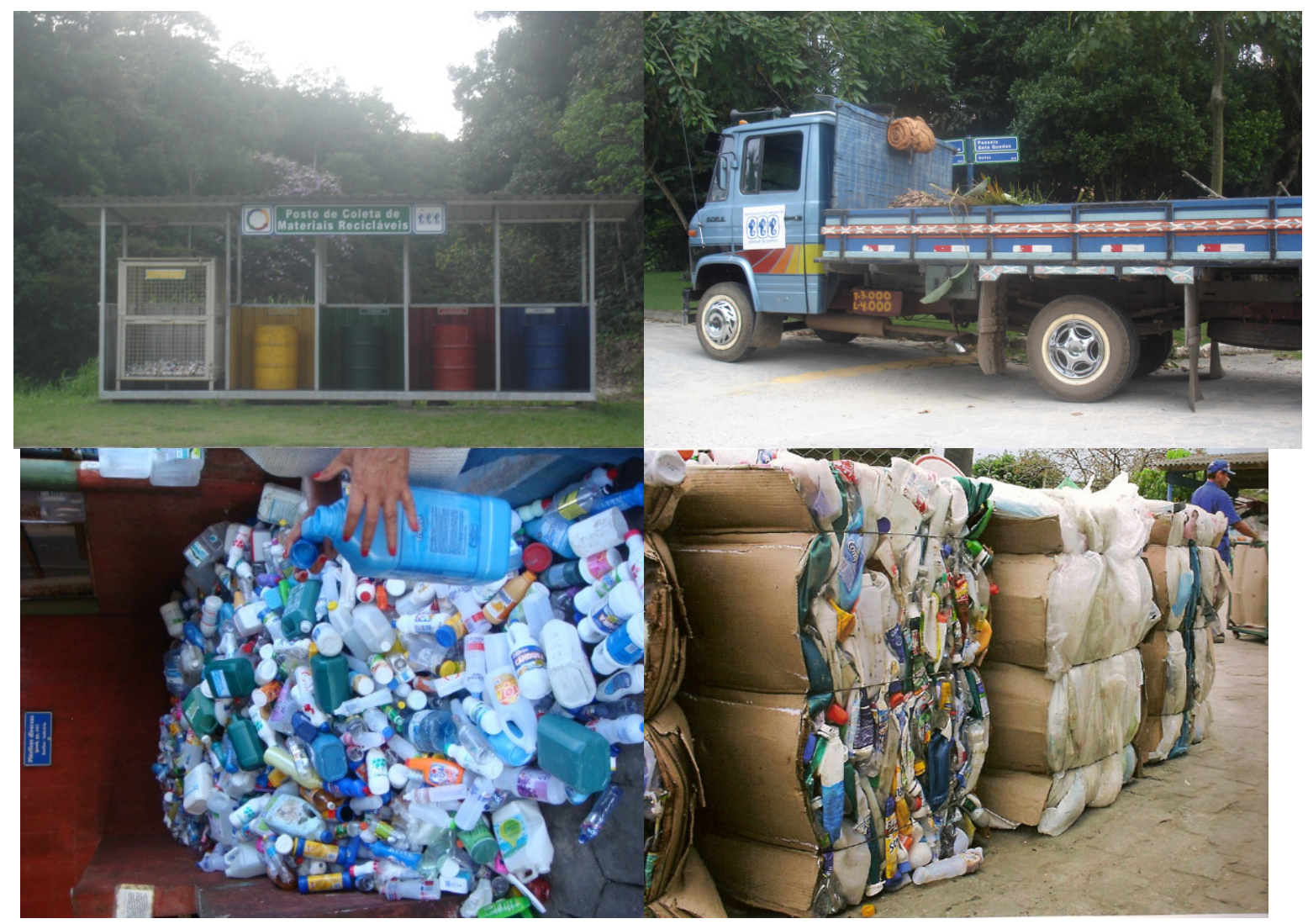

Figura 3 - Coleta Seletiva de lixo na Riviera de São Lourenço. Fotos: Ana Alípio, 2008. Montagem de fotos tiradas em visita aos postos de coleta e ao Centro de Gerenciamento dos Resíduos. 


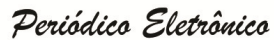 Fórum Ambiental}
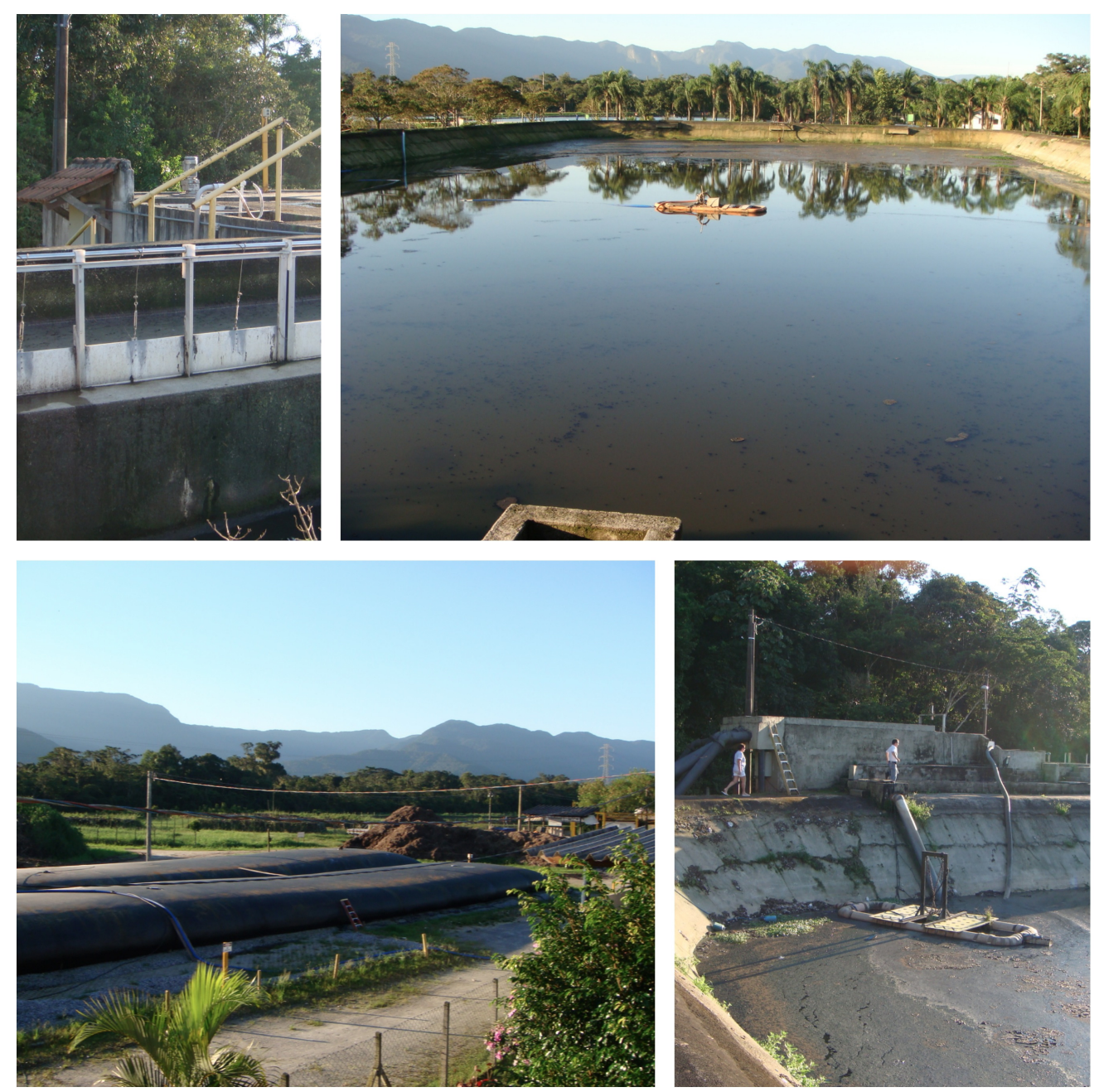

Figura 4 - Fotos por Ana Alipio, Tiradas no centro de Tratamento de agua da RSL, (montagem criada no programa foto photo, editada por Alipio, 2013)

A gestão dos Resíduos sólidos urbanos que desde 1983 a Construtora Sobloco junto com a Associação dos Amigos da Riviera, desenvolve um programa completo de Gerenciamento. O objetivo desse gerenciamento é Reduzir o volume de resíduos gerados na Riviera destinados ao aterro controlado do município, reaproveitar os resíduos, diminuindo o desperdício de materiais e envolver a comunidade no equacionamento do problema do lixo e da manutenção da qualidade ambiental. (SOBLOCO- Programa de Resíduos Sólidos Riviera de São Lourenço, 2006)

A separação é feita pelos moradores, que são incentivados pela própria infraestrutura existente. Apos essa separação os moradores das residências descartam o lixo nos pontos de coleta espalhados em toda a zona residencial. Na área denominada 
zona turística onde se localizam os prédios, a coleta seletiva é feita nos andares separadas pelos moradores e recolhida pelo condomínio e entregues ao caminhão coletor.

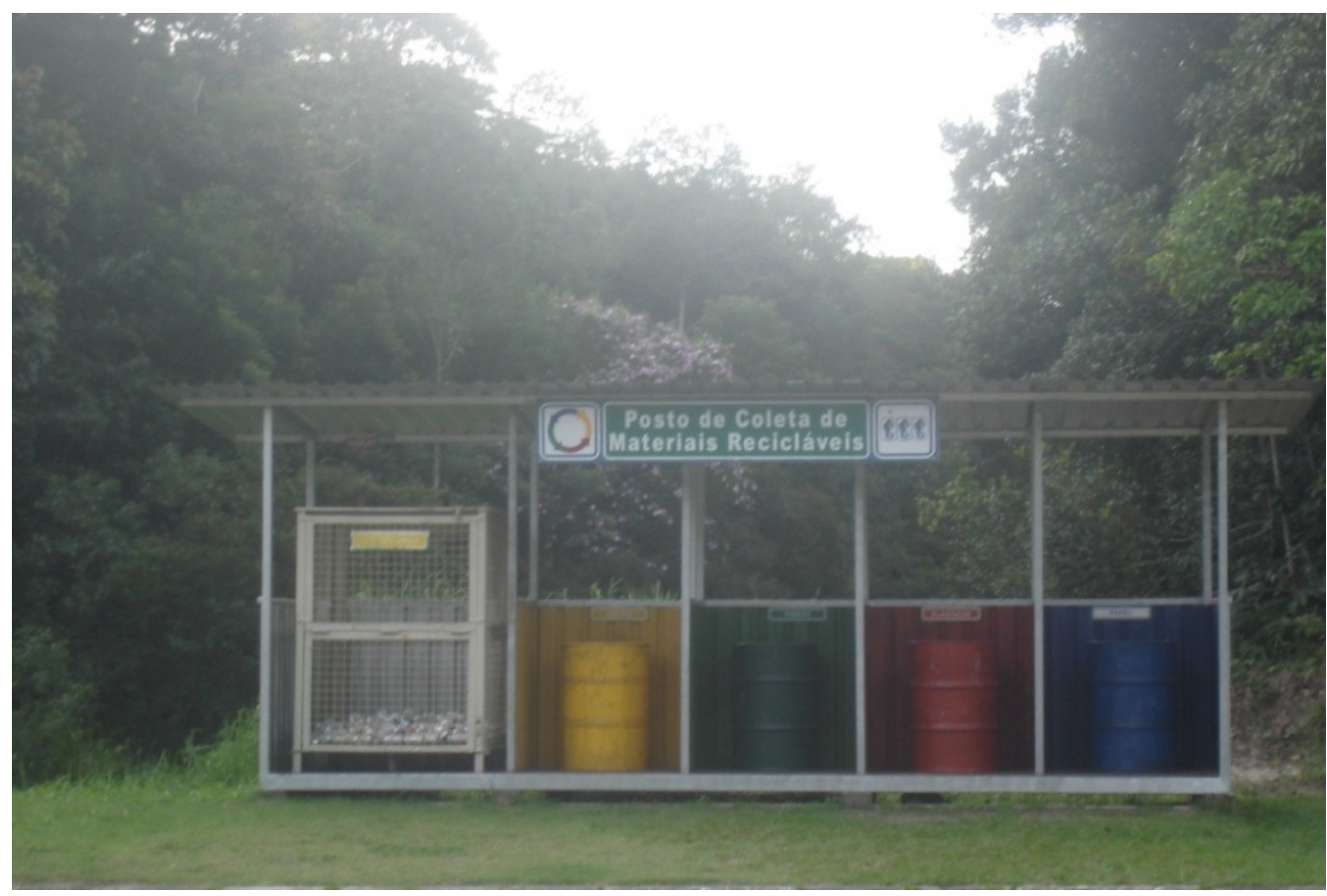

Figura 5 - Fonte: Alipio, 2008 Foto retirada em um ponto de Coleta dos Resíduos, da área residencial, onde o morador faz uma previa separação.

Após a separação os resíduos são encaminhados para o destino correto de acordo com sua categoria.

A venda dos materiais eh feita pela AARSL e o lucro vai para Fundação 10 de Agosto $^{10}$. A média de entulho gerenciado é de 11 toneladas /mês.

Para implantação desse programa junto aos funcionários do condomínio, foram necessários significativos investimentos na área de educação ambiental. Através de palestras, workshops, encontros, folhetos e outras ações os organizadores foram

\footnotetext{
${ }^{10}$ A Fundação 10 de Agosto, entidade social e educativa, sem fins lucrativos, com sede na Riviera de São Lourenço- Bertioga, SP tem como visão para sua existência proporcionar educação e qualificação profissional para a população de Bertioga. Oferece cursos gratuitos, seja através da música, esportes e artes manuais para jovens e crianças, ou através de cursos técnicos profissionalizantes para jovens e adultos. Fonte: http://www.rivieradesaolourenco.com/wp-content/uploads/ApresentacaoFundacao10deagosto2012.pdf acesso 07 de Outubro de 2013.
} 
conquistando a adesão e participação da população fixa e flutuante da Riviera de São Lourenço ao programa.

TABELA 2 - RESIDUOS COLETADOS PELA RSL

\begin{tabular}{|l|l|}
\hline Materiais coletados até agosto de $\mathbf{2 0 1 2}$ & Peso $(\mathbf{K g})$ \\
\hline Papelão & 1.821 .176 \\
\hline Papéis mistos & 261.107 \\
\hline Alumínio & 54.933 \\
\hline Ferro & 396.588 \\
\hline PET & 65.364 \\
\hline Plástico & 414.261 \\
\hline Vidro & 831.485 \\
\hline Total & 3.844 .914 \\
\hline
\end{tabular}

Fonte: Revista HYYPOCAMPOS, 2013.

A coleta seletiva GRS gera todos os meses toneladas de resíduos e até o mês de agosto de 2012 a coleta seletiva gerou 3,8 milhões $\mathrm{kg}$ de resíduos que foram encaminhados para a reciclagem. $\mathrm{O}$ gerenciamento do lixo vem sendo implantado desde 1992.

Esse programa atingiu proporções significativas em relação ao gerenciamento de resíduos, realizados pela iniciativa privada no país. A RSL tem programa pioneiro em Gerenciamento de Resíduos e é considerada a melhor experiência brasileira no campo de coa de acordo com pesquisa feita na Universidade Federal Fluminense UFF/CIRS.

A Sobloco mostrou que a iniciativa privada pode e deve estar junto do poder público e da população na busca de soluções para uma melhor qualidade de vida.

Tornando-se hoje este programa um dos maiores trabalhos deste gênero desenvolvido pela iniciativa privada no Brasil ${ }^{11}$.

${ }^{11}$ (http://www.rivieradesaolourenco.com/web/site/Educacao.Coleta.asp) 


\section{LEIS PERTINENTES}

A lei em que sustenta o artigo é a Lei de Politica Nacional de Resíduos Sólidos (PNRS) aprovada pela lei 12.305/10, que demonstra a importância do planejamento na gestão dos resíduos sólidos ao permitir o acesso de ações e programas relacionados ao seu manejo de Resíduos Sólidos Essa lei procura implantar a coleta seletiva, a logística reversa e a compostagem dos resíduos ate o ano de 2014 , só permitindo a união firmar contratos para estados e municípios que tiverem com um plano de resíduos montado ${ }^{12}$.

Outra lei pertinente, eh a Lei Federal No 11.445, de 05/01/2007, dispõe sobre as Diretrizes Nacionais para o Saneamento Básico considera: no Art. 3 ,o saneamento básico como: abastecimento de água potável; esgotamento sanitário; limpeza urbana e manejo de resíduos sólidos; drenagem e manejo das águas pluviais urbanas. A limpeza urbana assim como o manejo de Resíduos sólidos, de acordo com a lei é considerada serviços públicos..

[...] compostos pelas atividades de: coleta, transbordo e transporte dos resíduos; triagem para fins de reuso ou reciclagem; tratamento, incluindo compostagem, e disposição final dos resíduos. Refere-se também ao lixo originário da varrição, capina e poda de árvores em vias e logradouros públicos e outros serviços de limpeza pública urbana, relacionados no art. 30 da Lei. (GUIA DE ELABORAÇÃO DE PLANOS DE GESTÃO DE RESÍDUOS SÓLIDOS MMA.)

Essa lei é ferramenta contra o acumulo de resíduos pois demonstra a obrigatoriedade dos serviços públicos a prestarem serviços de saneamento básico. Porem, embora tenha entrado em vigor há mais de cinco anos, não certifica que as metas de água e esgotos sejam. De acordo com Almeida a última Pesquisa Nacional de Saneamento Básico (PNSB) do IBGE, referente a 2008, realizada em convênio com o Ministério das Cidades, com a participação de pesquisadores da Fundação Oswaldo Cruz (Fiocruz) e técnicos especialistas, demonstrou que a situação ainda é grave no País, e não ocorreram grandes avanços nos últimos anos.

A nova Política Nacional de Resíduos Sólidos proíbe a manutenção de lixões após 2014, mas os números expressam uma realidade que dificilmente poderá ser alterada em

\footnotetext{
${ }^{12}$ MINISTÉRIO DO MEIO AMBIENTE.ICLEI - Brasil. Plano de gestão de resíduos sólidos: manual de orientação Brasília, 2012, p.08
} 
curto prazo pela lei ${ }^{13}$.

De acordo com o Estatuto da Cidade, as políticas públicas devem prever a participação e controle social. A quantidade de fatores que envolvem a aplicação dessa lei, assim como todos os participantes diretos e indiretos, demonstra o motivo da dificuldade de sua aprovação. Por outro lado, a lei também afeta áreas que tem interesse que ela se aplique, como por exemplo, o lucro com uma gestão adequada de resíduos sólidos. A logística reversa é um instrumento que prevê a restituição dos resíduos sólidos para seus geradores.

\section{CONCLUSÕES}

A Construtora Sobloco tem consciência dos danos que o resíduo pode fazer ao meio ambiente, além das limitações técnicas, financeiras e operacionais do poder público para sua correta coleta e tratamento.

O GRS depende de diversos fatores, fatores não apenas oriundas do serviço municipal, como provedor de saneamento e infraestrutura para o recolhimento de lixo, mas, também da população em si que muitas vezes tem seus valores ligados ao nível educacional, poder aquisitivo, hábitos e costumes dessa população, além de fatores climáticos e demográficos. Um programa bem elaborado de reeducação da população com relação à geração e à deposição de resíduos sólidos poderá contribuir para minimizar impactos ao meio ambiente.

Um meio ambiente equilibrado traduz-se pela qualidade da vida das pessoas que 0 usufruem e decorre de um planejamento urbano eficiente, traduzido em esgoto tratado, água potável, lixo coletado, parques e áreas verdes, ciclovias, segurança, educação, saúde, transporte, energia e mobilidade.

No caso de Bertioga, a Lei se aplica em algumas áreas, principalmente em uma área controlada pela iniciativa privada. A Riviera de São Lourenço comprova que o GRS (gerenciamento de resíduos), é possível e tem grande resultado quando há integração da Gestão partindo do interesse do poder publico ou privado.

\section{REFERÊCIAS BIBLIOGRAFICAS}

\footnotetext{
${ }^{13}$ Fonte: Artigo http://www.rivieradesaolourenco.com/insustentavel-leveza-dasustentabilidade/
} 
ABRELPE e PLASTIVIDA - Caderno Informativo de recuperação energética. 2010-2011. Disponível em: http://www.abrelpe.org.br/_download/informativo_recuperacao_energetica.pdf

ALÍPIO, Ana Paula Rattis. Dissertação (Mestrado em Arquitetura e Urbanismo) - Reciclagem do entulho da indústria da construção

Universidade Presbiteriana Mackenzie, São Paulo, 2010.

ALÍPIO, Ana Paula Rattis. Seminário de Tese III e IV - Gestão De Resíduos Sólidos -Caso No Litoral Do Estado De Sao Paulo .Universidade Presbiteriana Mackenzie, São Paulo, 2013

ALVES, C. A. T. Gestão Eficiente dos Resíduos, 2005.

ASSOCIAÇÃO BRASILEIRA DE NORMAS TÉCNICAS. NBRISO 14001: Sistemas de gestão ambiental Especificação e diretrizes para uso. Rio de Janeiro, 1996.

BRASIL. Ministério do Meio Ambiente. Conselho Nacional do Meio Ambiente CONAMA. Resolução no 307 de 05 de julho de 2002. Estabelece diretrizes, critérios e procedimentos para gestão dos resíduos da construção civil.

DIAS, Sylmara Goncalves. Impactos Ambientais e Sociais do tratamento e disposição de Resíduos Sólidos Urbanos . Estudo dos Aspectos Sociais Envolvidos. Autor- Curso de gestão Ambiental- EACH- USP. PROCAM USA. 2013

IBGE - Instituto Brasileiro de Geografia e Estatística. Disponível em:

http://www.ibge.gov.br/cidadesat/xtras/perfil.php?codmun=350635 acesso 01 de Setembro de 2013.

IBGE - Instituto Brasileiro de Geografia e Estatística. Disponível em:

http://www.ibge.gov.br/cidadesat/painel/painel.php?codmun=350635\&search=sao- paulo|bertioga\#historico) 2013.

ICLEI - Brasil. Planos de Gestão de Resíduos Sólidos: Manual de Orientação. Apoiando a implementação da Política Nacional de Resíduos Sólidos: do nacional ao local. Ministério do meio Ambiente. $\square$ Brasília, 2012.

GOMES, AQUINO e COLTURATO. Bimetrização seca de resíduos sólidos: estado da arte e análise crítica das principais tecnologias. Revista Eng. Sanit. Ambient, v.17 n.3, jul set 2012 pag 296.

http//www.scielo.br/pdf/esa/v17n3v17n3a06.pdf.

MAZZOLENIS, S. Riviera de São Lourenço Ontem, hoje. Registros, 2008; a book editor. São Paulo.

PANIZZA, A. C. Imagens orbitais, cartas e coremas: uma proposta metodológica para o estudo da organização e dinâmica espacial. Aplicação ao Município de Ubatuba, Litoral Norte, Estado de São Paulo, Brasil [Tese]. Universidade de São Paulo, 2004.

PINTO, Tarcísio de Paula, Tese - Metodologia para a gestão diferenciada de resíduos sólidos da construção urbana. PCC-USP, 2008

SMA-CETESB-ABES. Aproveitamento energético dos resíduos Sólidos, setembro de 2011. Disponível em: http://cenbio.iee.usp.br/download/documentos/apresentacoes/cetesb2011_suani.pdf acesso 14 de abril de 2013.

http://www.sobloco.com.br/site/interno.asp?keyword=realizacoes.desenvolvimento http://www.rivieradesaolourenco.com/planejamento-urbano-para-um-meio-ambiente-equilibrado/ 
